\title{
STIFFNESS AFTER FRACTURES AROUND THE KNEE IN SPINA BIFIDA
}

\author{
K. J. DRABU, GEOFFREY WALKER \\ From Queen Mary's Hospital for Children, Carshalton
}

\begin{abstract}
A study was made of knee stiffness after fractures around the knee in patients with spina bifida. Thirtyone patients with $\mathbf{4 5}$ fractures were followed up for $\mathbf{2}$ to 15 years after the fracture. Knee stifiness was found in $67 \%$ of patients; this amounted to loss of up to half the normal range of movement.

The stifiness appeared at two months from the time of the fracture and was established by six months. However, in all patients it had resolved by three years, so that their mobility was not affected in the long term. It is concluded that though stifiness is common after fractures in patients with spina bifida, it should be treated expectantly as it will resolve within three years without specific treatment.
\end{abstract}

Fractures of the lower limbs in spina bifida are relatively common. Those occurring around the knee, whether simple fractures or fracture-separation of epiphyses, have in our experience often been followed by knee stiffness.

Several studies have been carried out on the treatment and radiological appearance of lower limb fractures in spina bifida (Eichenholtz 1963; Thompson, Cavin and Phippen 1964; Conner 1970). However, we are unaware of any study of the natural history of knee stiffness after such fractures.

This paper describes the natural history of the condition, outlines the short-term effects of knee stiffness on the mobility of these patients, and reports the restoration of normal movement within three years.

\section{MATERIAL AND METHODS}

A retrospective study was made of all those patients with spina bifida admitted to Queen Mary's Hospital for Children, Carshalton, between 1967 and 1980 , who had sustained fractures of the lower third of the femur or the upper third of the tibia. There were 31 patients with a total of 45 fractures. Their ages at review ranged from 5 to 22 years, with an average of 13 years. The male to female ratio was almost one to one, with 15 males and 16 females. Follow-up ranged from 2 to 15 years with an average of 9.7 years between fracture and review.

At the initial examination the neurological level of the spinal lesion and the muscle balance at the hips were

K. J. Drabu, FRCS, Tutor in Orthopaedics

University of Manchester, Department of Orthopaedic Surgery, Clinical Sciences Building. Hope Hospital, Eccles Old Road, Salford M6 8HD, England.

G. F. Walker, FRCS, Orthopaedic Surgeon

Queen Mary's Hospital for Children, Carshalton, Surrey SM5 4NR, England.

Requests for reprints should be sent to Mr K. J. Drabu.

(C) 1985 British Editorial Society of Bone and Joint Surgery $0301-620 X / 85 / 2059 \$ 2.00$ recorded, and previous operations on the hips or knees were noted. After the fracture, three factors were reviewed at regular intervals:

1. Knee deformity.

2. The passive range of movement at the knee.

3. The mode of mobility of the patients.

These factors were studied at three months, six months and annually from the time of the fracture until completion of the study. The cause of the fracture and the method of treatment also were recorded.

\section{RESULTS}

The age at which the fractures occurred ranged from 1 to 13 years with a mean of 5.6. Of the 31 patients studied, 13 were below the age of walking at the time of fracture, 2 were wheelchair dependent, 13 walked with the help of long-leg calipers, 1 walked with the aid of a short iron and 2 walked unaided.

Thirty of the 45 fractures $(67 \%)$ were followed by knee stiffness, 12 knees remained mobile, and three had increased movement.

In the 30 knees that developed stiffness, the decrease in passive range was noted as early as two months from the time of fracture and in all cases it was established by six months. The mean loss of movement was $58^{\prime \prime}$, or nearly half the normal range. By two years 24 of the 30 stiff knees had regained a full range of movement; at the end of three years the remaining six were left with a final loss of movement of $10^{\circ}$ or less. This slight residual stiffness did not influence their mode of mobility.

Twenty of the 45 fractures in the series (44\%) were directly related to some form of treatment; that is, in all cases the fracture occurred within two weeks of the removal of a plaster cast or an operation on the limb. The remaining 25 fractures were not associated with any form of treatment; only 9 of these were the result of direct trauma, the remainder presenting as red warm 
swollen knees. The incidence of fractures in relation to age and to form of treatment is shown in Figure 1.

With regard to treatment, 19 of the fractures were treated in a Robert Jones bandage, 12 with skin traction, 9 in plaster casts and 5 had no formal treatment. When possible the patients also had physiotherapy, including regular passive stretching once the fracture was felt to be stable. This, however, did not seem to influence the natural progress of the stiffness.

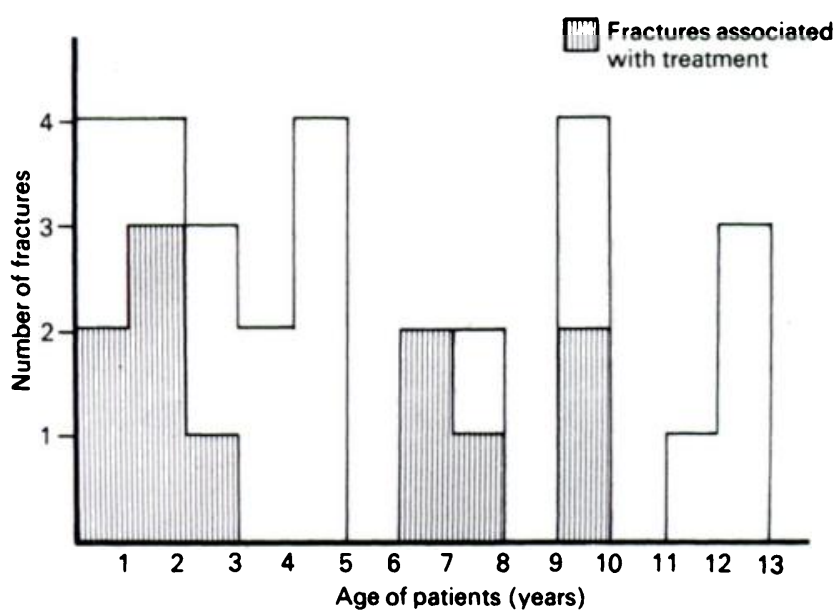

Fig. 1

Relationship between age of patient, incidence of fracture and form of treatment.

In an attempt to establish whether age affected the degree or incidence of stiffness, the patients were arbitrarily divided into two groups: those above the age of seven years at the time of fracture, and those below. The average loss of passive movement at the knee was $50^{\circ}$ in those above the age of seven and $55^{\circ}$ in those below. This difference is not statistically significant.

Exuberant callus has been described as a common sequel to fractures in paralysed limbs (Robin 1965; Navarro Quilis 1974; Parsch and Manner 1976). As it was seen both in fractures that did develop knee stiffness and in those that did not, callus and stiffness were felt to be unrelated. The site of the fracture, whether tibial or femoral, did not influence the rate of return of knee movement. However, a previous fracture around the knee delayed the final return of movement, though it did not influence the excellent range achieved three years after the fracture.

\section{CONCLUSION}

This study has shown that knee stiffness after fractures around the knee is a common problem in children with spina bifida, but a temporary one. While the loss of movement may diminish walking activity for some months after the fracture, the final result after three years is good, with return of virtually normal knee movement. Consequently, these patients can be treated expectantly as, in the long term, there will be no decrease in walking potential. This natural history is not significantly modified by age, the site of the fracture, or its method of treatment; so perhaps physiotherapy should be reserved for other purposes.

We would like to express our thanks to $\mathrm{Mr} \mathrm{P}$. Cheong-Leen, Consultant Orthopaedic Surgeon at Queen Mary's Hospital for Children, Carshalton, for allowing us access to the records and radiographs, and patients under his care; and to Mrs A. W. Hockenhull, at The University Department of Orthopaedics, Hope Hospital, for her assistance in typing the manuscript.

\section{REFERENCES}

Conner AN. The treatment of flexion contractures of the knee in poliomyelitis. J Bone Joint Surg [Br] 1970;52-B: 138-44.

Eichenholtz SN. Management of long-bone fractures in paraplegic patients. J Bone Joint Surg [Am] 1963;45-A:299-310.

Navarro Quilis A. Fractures in children with myelomeningocoele: report of 15 cases and a review of the literature. Acta Orthop Scand 1974;45:883-97.

Parsch K, Manner G. Prevention and treatment of knee problems in children with spina bifida. Dev Med Child Neurol 1976:Suppl. 37:114-6.

Robin GC. Fracture in childhood paraplegia. Paraplegia 1965;3: 165-70.

Thompson MS, Cavin E, Phippen WG. Fractures of the femora associated with spina bifida. Milit Med 1964:129:841-4. 